\title{
COMMENT
}

\section{A year without touch: a reflection on physician-patient interaction during COVID-19}

\author{
Teresa Vente ${ }^{1}$ \\ Pediatric Research (2021) 90:1115-1116; https://doi.org/10.1038/s41390-021-01390-0
}

\begin{abstract}
"Call you when I land?" I said as I zipped up my parka and grabbed my weekend travel bag headed to the airport. It was supposed to be a routine "goodbye till next time" as I left my partner, a practicing cardiologist in Toronto, and headed back to my home in Chicago where I practice pediatric palliative care. That was February and little did we know this would be our last time together for the foreseeable future. Now, almost a year later, the dog days of summer have come and gone, and the crisp cool days of fall have passed, and winter seems here to stay. The passing time has felt almost surreal, as days melted together and there is
\end{abstract} near constant uncertainty.

My experience is not unique. The news and social media have been filled with personal stories of people cut off from their loved ones, friends, and support networks. Children and spouses cannot visit a loved one in long-term care; grandparents sit isolated from grandchildren; children no longer play with neighbors; and colleagues across all disciplines, from restaurant workers to bankers, live with some level of separation. The sequestration and protection loom more apparent in hospitals where visitors are limited if allowed at all and clinicians must don layers of personal protective equipment to enter a patient room. The risk of exposure is real, and hospitals have been forced to make difficult decisions to limit providers to "essential" or "necessary" patient contact. In some cases, this has led to fewer visits by staff such as social workers, chaplains, and even palliative care clinicians. When these visits are not deemed essential or patient encounters are transitioned to virtual visits, vulnerable patients have limited opportunities for healing touch.

Touch is a fundamental part of our human experience. It is a very important way in which we get information from our environment and is an essential mode of non-verbal communication. $^{1-3}$ The importance of touch begins in infancy, first described in animal models almost a century ago with behaviors in rat pups and later in Harry Harlow's famous work with primates isolated from maternal touch. ${ }^{4}$ Animal models have now identified that touch deprivation results in disruption to hormonal signaling and negative effects on growth and development. ${ }^{5}$ Similar concerns for the negative effects of touch deprivation have been raised in neonates, where touch facilitates the way humans come to appreciate their own bodies and their sense of self. ${ }^{2,5}$ Studies of neonates have shown that touch has positive effects on regulatory functions, including body temperature, respirations, and feeding. ${ }^{2}$ In studies of hospitalized infants, touch is associated with increased weight-gain, analgesia, and shorter hospital stays. ${ }^{2}$ Psychological studies pioneered by psychoanalyst Rene Spitz and psychologists John Bowlby and Mary Ainsworth have shown that touch is fundamental to development of secure attachment in early childhood. ${ }^{2,4,6}$ Touch is central to socialization and play among children as interactions expand beyond immediate family and caregivers. ${ }^{2}$

The association of touch with healing is long-standing, particularly within religious and spiritual practice. The role of touch in the physician-patient relationship has been described since the dawn of medical practice in both Eastern and Western civilizations. $^{1}$ Medical literature over the past 50 years has identified two main categories of touch between physicians and patients: touch related to tasks or procedures and touch related to expression or caring. ${ }^{1,6,7}$ Expressive or caring touch provides nonverbal communication through which providers can emote, thus establishing a bond and building rapport with patients., ${ }^{1,6}$ Observational studies have shown improvements in patient satisfaction, level of comfort and compliance even with minimal provider-to-patient touch. ${ }^{6}$ In geriatric patients and patients with serious illness, touch has been associated with many positive benefits including physical and psychological comfort, reorientation from confusion, and reduction in perception of isolation. ${ }^{6,7}$ In the last two decades, psychological evidence has supported the theory that touch communicates several distinct emotions, including those relevant to caregiving such as love, gratitude, and sympathy. ${ }^{8}$ More recently, advances in neuroscience have shown that touch can modulate electrophysiological measures of situational empathy in those experiencing pain. ${ }^{9}$

As mentioned, the current viral pandemic has engendered significant obstacles to engaging in touch, not just clinician-topatient contact. Of course, barriers to touch within medicine existed prior to the onslaught of COVID. When assessing medical provider and patient comfort with touch, studies have shown that both experienced providers and trainees feel that touch enhances physician-patient interaction and communication; however, these studies identified concerns about risks associated with touch such as uncertainty about the appropriate level of intimacy or interaction with a patient of the opposite gender or the potential for misinterpretation. ${ }^{10}$ Such worries about touch are typically higher among male trainees and providers and have especial perceived or acknowledged cultural differences between patients and providers. ${ }^{10}$ When evaluating how trainees in medicine are taught about methods of non-verbal communication, including touch, studies have shown that formal discussions of touch were largely absent from curriculum. ${ }^{10}$ While some patients expressed concerns related to touch from clinicians they did not know well and from clinicians of the opposite gender, patients were notably open to touch, especially in the context of distress. ${ }^{3}$

\footnotetext{
1Ann \& Robert H. Lurie Children's Hospital of Chicago, Chicago, IL, USA

Correspondence: Teresa Vente (tvente@luriechildrens.org)
}

Received: 22 December 2020 Revised: 4 January 2021 Accepted: 13 January 2021

Published online: 18 February 2021 
Most striking about the research about perceptions of touch is both fears of being vulnerable by allowing oneself to be touched alongside the intense desire to be comforted by touch when at our most vulnerable. For now, my partner in Canada and I remain isolated from one another, as Covid-19 continues to force separations across international borders, state-lines, screen doors, and hospital rooms. However, we must not forget the value of non-verbal communication, especially for those most vulnerable. Let us remember the healing power of touch, even when other therapies have failed; touch can provide an outlet for patients' and our own feelings when words fail to bring comfort. We should continue to take necessary precautions against exposure and infection without having to endure another year without touch.

\section{ACKNOWLEDGEMENTS}

Jeremy Kobulnik, MD, MHSc and Joel Frader, MD.

\section{AUTHOR CONTRIBUTIONS}

T.V. is the sole author and contributor for this manuscript.

\section{ADDITIONAL INFORMATION}

Competing interests: The author declares no competing interests.
Publisher's note Springer Nature remains neutral with regard to jurisdictional claims in published maps and institutional affiliations.

\section{REFERENCES}

1. Bruhn, J. G. The doctor's touch: tactile communication in the doctor-patient relationship. South Med. J. 71, 1469-1473 (1978).

2. Cascio, C. J., Moore, D. \& McGlone, F. Social touch and human development. Dev. Cogn. Neurosci. 35, 5-11 (2019).

3. Osmun, W. E., Brown, J. B., Stewart, M. \& Graham, S. Patients' attitudes to comforting touch in family practice. Can. Fam. Physician 46, 2411-2416 (2000).

4. Van der Horst, F. C. \& van der Veer, R. Loneliness in infancy: Harry Harlow, John Bowlby and issues of separation. Integr. Psychol. Behav. Sci. 42, 325-335 (2008).

5. Schanberg, S. M. \& Field, T. M. Sensory deprivation stress and supplemental stimulation in the rat pup and preterm human neonate. Child Dev. 58, 1431-1447 (1987).

6. Bush, E. The use of human touch to improve the well-being of older adults. A holistic nursing intervention. J. Holist. Nurs. 19, 256-270 (2001).

7. Sims S. The significance of touch in palliative care. Palliative Med. 2, 58-61 (1988)

8. Hertenstein, M. J., Keltner, D., App, B., Bulleit, B. A. \& Jaskolka, A. R. Touch communicates distinct emotions. Emotion 6, 528-533 (2006).

9. Peled-Avron, L., Goldstein, P., Yellinek, S., Weissman-Fogel, I. \& Shamay-Tsoory, S. G. Empathy during consoling touch is modulated by mu-rhythm: an EEG study. Neuropsychologia 116, 68-74 (2018).

10. Kelly, M. et al. Being vulnerable: a qualitative inquiry of physician touch in medical education. Acad. Med. https://doi.org/10.1097/ACM.0000000000003488 (2020). 